\title{
Enhanced and coordinated processing of synapsed viral DNA ends by retroviral integrases in vitro
}

\author{
George Kukolj and Anna Marie Skalka ${ }^{1}$ \\ Institute for Cancer Research, Fox Chase Cancer Center, Philadelphia, Pennsylvania 19111 USA
}

\begin{abstract}
We have designed novel substrates to investigate the first step in retroviral integration: the site-specific processing of two nucleotides from the 3' ends of viral DNA. The substrates consist of short duplex oligodeoxynucleotides whose sequences match those of the U3 and U5 ends of viral DNA but are covalently synapsed across the termini by short, single-strand nucleotide linkers. We show here that the optimal separation between termini in a synapsed-end substrate for avian sarcoma/leukosis virus (ASV) IN is 2 nucleotides. This places the two conserved $5^{\prime}-\mathrm{CA}-3^{\prime}$ processing sites 6 nucleotides apart, a separation equal to the staggered cut in target DNA produced by this enzyme during the subsequent joining reaction. Based on estimates of initial reaction rates, this synapsed-end substrate is processed by IN at $>10$-fold higher efficiency than observed with an equivalent mixture of U3 and U5 single-end (uncoupled) substrates. Enhanced processing is maintained at low IN concentrations, suggesting that the synapsed-end substrate may facilitate enzyme multimerization. Enhanced processing by HIV-1 IN, which produces a 5-bp stagger during integration, was observed with a synapsed-end substrate in which the separation between processing sites was 5 nucleotides. These observations provide estimates of the distances between active sites in the multimeric IN-DNA complexes of ASV and HIV-1. Our results also show that processing of paired U3 and U5 ends need not be coupled temporally. Finally, we observed that substrates that paired a wild-type with a mutated terminus were cleaved poorly at both ends. Thus, in vitro processing of the synapsed-end substrates requires specific recognition of the sequences at both ends. These findings provide new insights into the mechanism of integrative recombination by retroviral integrases and, by extension, other prokaryotic and eukaryotic transposases that are related to the viral enzymes.
\end{abstract}

[Key Words: Retrovirus; HIV; ASV; integrase; LTR; transposition]

Received June 1, 1995; revised version accepted August 31, 1995.

Integration of a DNA copy of the viral RNA genome into a host chromosome is an essential step in the retroviral replication cycle (for review, see Goff 1992; Katz and Skalka 1994; Vink and Plasterk 1994; and references therein). Reverse transcription produces a linear, doublestranded DNA copy of the viral genome. The blunt ends of this molecule contain cis-acting sequences that serve as the attachment sites for integration into host chromosomal DNA. The attachment sites do not reside at the exact termini of the viral DNA but are flanked by (usually) 2 bp on both ends. The first step in the integration process involves endonucleolytic cleavages at the 3 ' ends of both strands, which remove 2 nucleotides from each terminus (Fig. 1A, step 1). This processing reaction produces new, recessed $3^{\prime} \mathrm{OH}$ ends adjacent to a CA dinucleotide that is conserved among all retroviruses and several other transposable elements. The viral DNA ends are thus prepared for subsequent nucleophilic attack on the phosphodiester backbone in host DNA. In the next

${ }^{1}$ Corresponding author. step (Fig. 1A, step 2), a concerted cleavage and ligation reaction joins the new 3 '-ends of viral DNA to 5 '-phosphates on host DNA. The insertion sites on the target DNA are on opposing strands and staggered by a few nucleotides, leaving gaps flanking the viral $5^{\prime}$-ends after joining. Removal of the $5^{\prime}$-overhanging ends of retroviral DNA and repair of the gaps in host DNA, may be accomplished by host cell repair enzymes, although integrase (IN) and perhaps other viral proteins could also play a role in these final steps (Chow et al. 1992; Sherman et al. 1992; Kulkosky et al. 1995). The length of the stagger, inferred from the size of the flanking duplication of host DNA at the site of integration, is unique to each virus or transposable element (Varmus and Brown 1989). Human immunodeficiency virus (HIV), like bacteriophage $\mathrm{Mu}$, produces a 5-bp duplication, whereas avian sarcoma and leukosis viruses (ASLV) and murine leukemia virus (MuLV) produce 6- and 4-bp duplications, respectively (Hishinuma et al. 1981; Muesing et al. 1985; Varmus and Brown 1989).

The retroviral protein that catalyzes integrative re- 


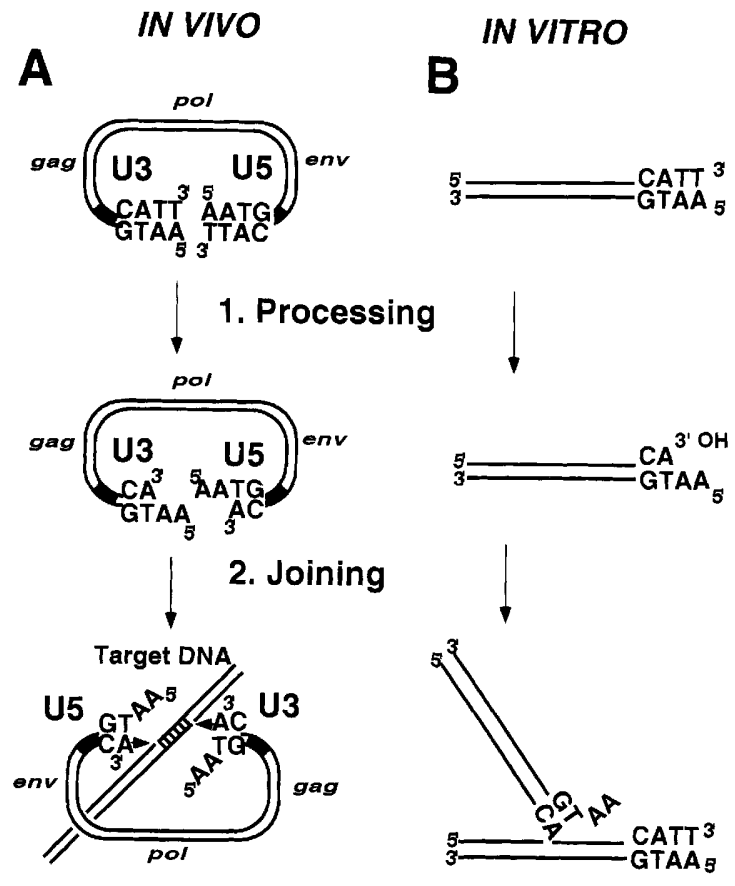

Figure 1. The two-step process of retroviral DNA integration. (A) Linear viral (ASV) DNA possesses conserved $5^{\prime}$-CATT-3' termini (and corresponding complimentary strands) that are processed to remove the TT dinucleotide from the $3^{\prime}$ end istep 1 , processing) and expose a pair of $5^{\prime}-\mathrm{CA}-3^{\prime} \mathrm{OH}$ ends. The two new ends are joined to a target site, in a 6-bp staggered fashion, through a concerted cleavage-ligation reaction (step 2, joining). (B) Schematic representation of in vitro assays of IN processing and joining activities utilizing single-end substrates that mimic one of the ends of retroviral DNA. The oligonucleotide substrates also can serve as surrogate target-site acceptors for joining with the processed precursors.

combination, IN, is encoded in the $3^{\prime}$ end of the pol gene. A useful assay developed to analyze IN activities uses short duplex oligodeoxynucleotides with sequences corresponding to either the U3 or U5 viral DNA ends and IN purified from bacterial expression systems (Katzman et al. 1989; Craigie et al. 1990; Katz et al. 1990). Such reconstituted systems have shown that IN functions as a multimer (Jones et al. 1992; Engleman et al. 1993; van Gent et al. 1993) and have made it possible to study details of the processing and joining of these singleended substrates in vitro (Fig. 1B). However, one limitation with this assay is that the major in vitro product represents a half-reaction in which only one viral DNA end is joined to a target site (Craigie et al. 1990; Katz et al. 1990). In contrast, reactions performed with preintegrative viral nucleoprotein complexes isolated from infected cells show a higher incidence of concerted integration events (Brown et al. 1987; Ellison et al. 1990; Farnet and Haseltine 1990; Lee and Coffin 1990). Moreover, analyses of DNA intermediates from viruses encoding mutations at one end indicated that IN must recognize both DNA ends for processing at either end to occur in vivo (Murphy and Goff 1992). It seems possible that a specific organization of the viral DNA termini in the preintegrative nucleoprotein complex may facilitate interaction of IN with both DNA ends.

To investigate this possibility, we designed a series of tethered oligodeoxynucleotide substrates that might structurally mimic a U3-U5 DNA end synapse (Fig. 2). The rationale for our design was based on the following assumptions: (1) models for retroviral integration predict that the coordinated interaction between ends is manifested through an IN-bound preintegration intermediate that has juxtaposed the viral DNA termini as illustrated in Figure $1 \mathrm{~A}$; (2) the distance separating the two processing sites in a synapsed intermediate may be related to the length of the stagger generated in the joining reaction (Fig. 1A, step 2); and (3) the "tether" introduced to link the two ends in such a substrate should permit both torsional and rotational flexibility across the end-to-end junction to accommodate IN-DNA interactions.

In this paper we test a series of these constructs as

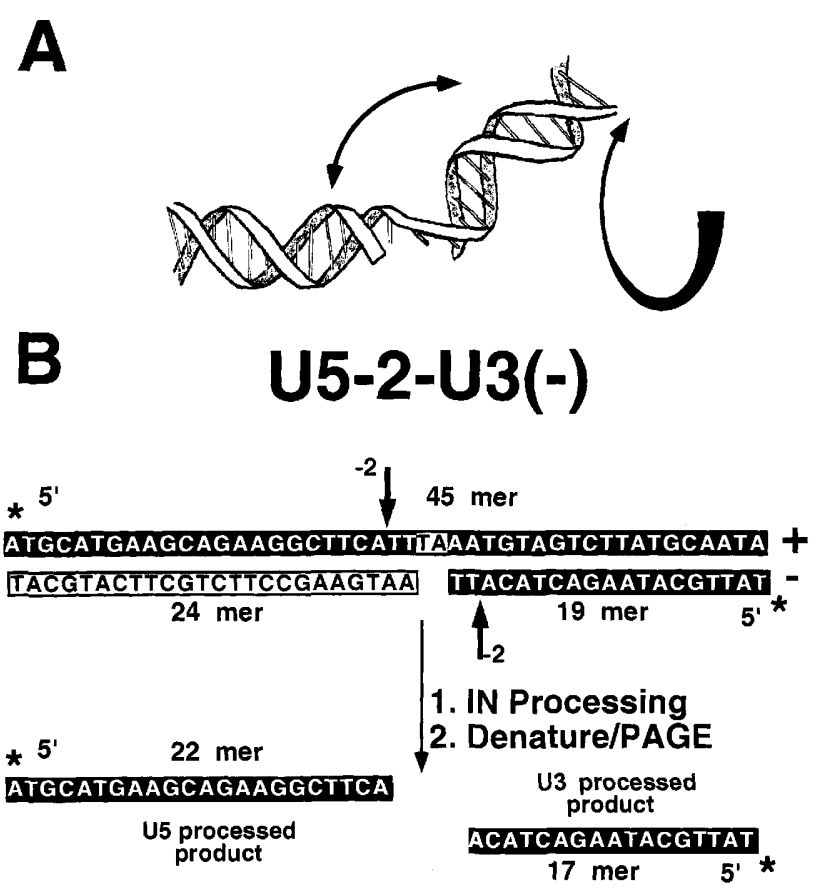

Figure 2. A flexible synapsed-end substrate and design of the cleavage assay. (A) Diagram of a B-DNA double helix with a central 2-bp gap. The helix can be divided into two topological domains, each with independent helical writhe. The singlestranded bridge provides for both angular and rotational flexibility (arrows). (B) Schematic representation of the two-ended ASV substrate U5-2-U3(-). This substrate contains a contiguous viral plus-strand, with an extra TA dinucleotide between the U5 and U3 junctions, and a 2-bp gap on the viral minusstrand that is provided by annealing of two separate oligonucleotides. Radioactively labeled strands are boxed and shaded. Processing of the U5 end is quantitated by the amount of radioactive 22-mer produced from unprocessed $5^{\prime}{ }^{32} \mathrm{P}$-radiolabeled 45 -mer. Processing of the U3 end is measured by the amount of radioactive 17 -mer produced from unprocessed $5{ }^{\prime}{ }^{32} \mathrm{P}$-radiolabeled 19-mer. Labeled ends are indicated with an asterisk $\left({ }^{*}\right)$. 
substrates for the IN-processing reaction. We demonstrate that synapsed-end substrates with distinct spatial separations between U3 and U5 terminal sequences are processed by ASV and HIV-1 IN at efficiencies that are significantly higher than those observed with uncoupled U3 and U5 single-end substrates. This is the first in vitro demonstration that IN preferentially processes synapsed viral DNA ends. We have investigated also a number of factors that may influence the coordinated interaction of retroviral DNA integrases with synapsed viral DNA ends. Results with the tethered substrates appear to be consistent with in vivo observations describing the coordinated processing and integration of retroviral DNA. They suggest that some of the limitations that have been observed with single-end substrates in vitro (low catalytic rates and absence of sequence specificity in DNA binding) may be attributable to the absence of specific substrate positioning that exists within the preintegration complex in vivo.

\section{Results \\ Design of a synapsed-end substrate and $a$ processing assay}

The organization of ends in the tethered substrate is intended to resemble that of synapsed viral DNA termini in a preintegration complex. It consists of sequences from two viral DNA termini, joined in an end-to-end fashion across only one of the DNA strands (Fig. 2). The tether linking the two ends is thus a covalent bridge of single-stranded DNA that can provide the torsional and rotational flexibility that may be required in a reconstructed U3-U5 synapse (Fig. 2A). The tether sequences are arbitrary, though where possible, we have chosen nucleotides that would create a unique restriction sites (i.e., SwaI) across these junctions. Figure 2B shows the nucleotide sequence of a tethered substrate for ASV IN, termed U5-2-U31-1, where the number 2 indicates the length of the tether in nucleotides and the minus $(-)$ denotes the strand in which a corresponding gap occurs. The tether links two viral DNA strands of the same polarity from opposite termini. Hence, the contiguous plus-strand in U5-2-U31- | spans both U5 and U3 sequence, whereas the discontinuity on the minus-strand is provided by two separate oligonucleotides.

To detect processing at U3 and U5 sites simultaneously, the synapsed-end substrates were designed with an inherent asymmetry. The length of the U3 and U5 portions, 19 and 24 bp respectively, are unequal and provide a means of distinguishing processed products from the respective ends. Two of the three strands in U5-2$\mathrm{U} 3$ ( - ) were radioactively labeled with ${ }^{32} \mathrm{P}$ : the U5 viral plus-strand end sequence, included in the contiguous 45 mer, and the U3 minus-strand end sequence, represented by the 19-mer. Cleavage immediately $3^{\prime}$ of the two conserved CA dinucleotides, as expected for the processing reaction, should produce two distinct products. U3 product can be quantitated by measuring the proportion of radioactive 19 -mer that is converted to a $17-$ mer; U5 product by measuring the proportion of radioactive 45mer converted to a 22-mer (Fig. 2B).

\section{Processing of a torsionally relieved synapsed-end substrate}

Figure 3A shows the time-dependent appearance of processed U5 and U3 products generated by ASV IN with the synapsed substrate described in Figure 2. In this, and all subsequent assays with ASV IN, we used a fixed concentration $(10 \mu \mathrm{M})$ of substrate with two different concentrations ( $350 \mathrm{nM}$ and $3.5 \mu \mathrm{M}$ in monomer subunits) of enzyme. To compare results from different assays, data are expressed as moles product per moles IN monomer in each reaction. As the data in Figure 3A show, significant quantities of specific U5 and U3 products, cleaved predominantly at the " -2 " but also at the " -3 " position,
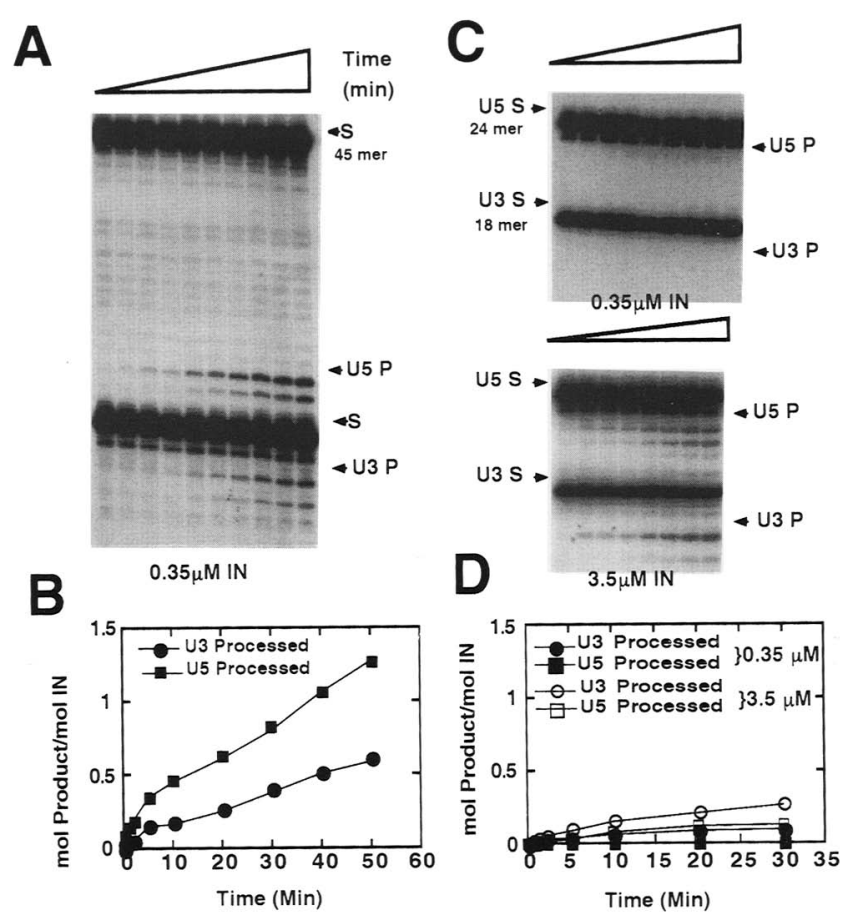

Figure 3. ASV IN processing of the synapsed-end substrate, U5-2-U3 - -) (A) The ${ }^{32}$ P-labeled substrate (see Fig. 2) at $10 \mu \mathrm{M}$ concentration was incubated with $0.35 \mu \mathrm{M}$ (monomer) ASV IN at $37^{\circ} \mathrm{C}$ in a standard reaction as described in Materials and methods. At the specified times (indicated in $B$ ), aliquots were removed and analyzed by denaturing PAGE. Arrows labeled "U5 P" and "U3 P" show the location of the processed products; the arrow labeled $\mathrm{S}$ shows the location of unprocessed substrate. (B) The U5 and U3 processed products were quantitated and plotted relative to molar equivalents of IN monomer as a function of time. (C) ASV IN processing of a mixture of uncoupled U5 and U3 duplex DNA substrates. U5 24-bp and U3 18-bp duplexes labeled at the 5 '-plus and 5 ' minus-strands, respectively, were used in standard reactions performed with 0.35 or $3.5 \mu \mathrm{M}$ ASV IN. The method of analysis and labeling of the arrows is as described in $A$. (D) Plots of uncoupled U3 and U5 processing relative to IN monomer concentration as a function of time. 
were detected with the synapsed-end substrate even at the lower concentration of enzyme. As expected, processing was more rapid with the higher concentration (not shown). The accompanying graph (Fig. 3B) shows that after $30 \mathrm{~min} \sim 0.8$ mole processed product $/ \mathrm{mole}$ IN was detected from the U5 end, and 0.4 from the U3 end (Fig. 3B). A preference for cleavage at the U5 end is not unexpected because retroviral integrases display differential reactivities with their respective end sequences in vitro.

Figure $3 \mathrm{C}$ shows the results of a control experiment that included a mixture of single-end substrates at analogous concentrations (10 $\mu \mathrm{M}$ of each end), but otherwise identical conditions. No product was detected at the lower enzyme concentration. This is consistent with our earlier results with a single-end U3 substrate, which showed that ASV IN activity is barely detectable at concentrations $<1-2 \mu \mathrm{M}$ (Jones et al. 1992). Both U5 and U3 products were detected at the higher IN concentration $(3.5 \mu \mathrm{M})$, but the amounts were much lower than what was observed with the synapsed-end substrate, even at a 10-fold-lower IN concentration (cf. Fig. 3, B and D). We conclude that the viral DNA end sequences are significantly better substrates for processing when presented in synapsed configurations. The fact that activity was detected at IN concentrations below what is estimated to be required for functional multimerization (Jones et al. 1992) suggests that the tethered substrates might actually facilitate effective multimer association.

\section{Processing of a torsionally constrained synapsed-end substrate}

The importance of synapse flexibility was investigated by testing a substrate with more rigid structure, imposed by a duplex tether (Fig. 4C). Although both strands in the U5-2-U3 substrate are contiguous, the separation between potential processing sites is equivalent to that in U5-2-U3(-), and ASV IN processing at these sites should produce cleavage products of the same size. The results show that no processing occurred with the U52-U3 duplex at the lower IN concentration (Fig. 4A). Inefficient use of this substrate was also apparent at the higher concentration, where a heterogeneous mixture of cleavage products was formed, presumably reflecting the low, non-specific endonuclease activity characteristic of ASV IN. From these results we conclude that torsionally constraining viral DNA end sequences may hinder their interaction with the IN proteins.

As illustrated in Figure 5, torsional restraints could also be relieved by introducing a gap in the plus strand of the synapsed-end substrate. Significant processing activity again was detected at the lower IN concentration. The amount of $\mathrm{U} 3$ product following a 30-min reaction was $0.8 \mathrm{~mole} / \mathrm{mole} \mathrm{IN}$, with an apparent cleavage rate similar to that observed with the U5-2-U3(-) substrate. In contrast to the minus-strand gapped substrate, ASV IN cleaves the U3 end more efficiently than the U5 end in a plus-strand gapped substrate. Only a small amount of U5 processed product was detected with the U5-2-

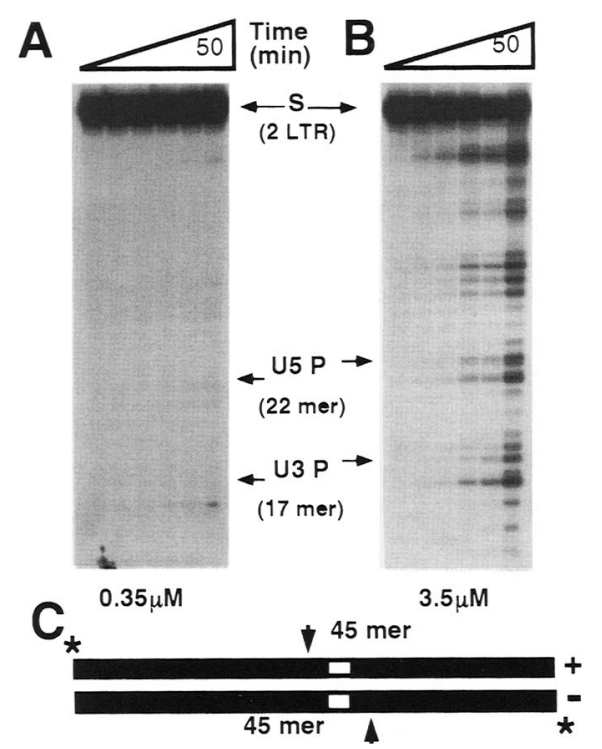

Figure 4. ASV IN processing of the torsionally constrained substrate, U5-2-U3. The U5-2-U3 substrate, with two $5^{\prime}{ }^{32} \mathrm{P}-$ radiolabeled contiguous 45 -nucleotide strands that contain an additional 2 bp between the U5 and U3 viral DNA end sequences was used in a standard processing assay. At the specified times $(0-50 \mathrm{~min})$ aliquots were analyzed as described in the legend to Fig. 3. Arrows indicate U5- and U3-specific processed products. (A) Results with $0.35 \mu \mathrm{MIN}$; $(B)$ results with $3.5 \mu \mathrm{M}$ IN; $(C)$ schematic representation of the two-LTR-containing substrate. Open rectangles represent tethering nucleotides.

$\mathrm{U} 3|+|$ substrate at both IN concentrations. Instead, we observed fairly rapid production of joined products that were longer than the 45-nucleotide radiolabeled-strand in the tethered substrate. Direct chemical sequencing of these products (data not shown) revealed that they were produced by joining of radioactively labeled U5 processed ends (22 mer) to the contiguous 45-nucleotide strands. The apparent rate of this joining reaction was higher than that observed with the single-ended substrates under similar conditions. It is unclear whether this represents an inter- or intramolecular reaction. However, it seems likely that some aspect of the conformation imposed by this tether facilitates a particular joining reaction.

What is the optimal spacing between processing sites in a synapsed-end substrate?

In design of the synapsed-end substrate, we assumed that an optimal separation between CA sequences might be similar to that observed for the coordinated joining of viral DNA ends to target DNA (i.e., 6 bp for ASV IN). To test the validity of this assumption we constructed U5$\mathrm{U} 3|+|$ and $\mathrm{U} 5-4-\mathrm{U} 3|+|$, two variants of the plus-strand gapped substrate described above that had alterations in gap and tether lengths. In substrate $\mathrm{U} 5-\mathrm{U} 3|+|$ the two end sequences are abutted, and the separation between processing sites is 4 nucleotides. The single-stranded tether bridging the minus-strand spans one phosphodi- 
Figure 5. ASV IN processing of the synapsed-end substrate, U5-2-U3 $1+1$. Method of analysis and labeling convention are as described in the legend to Fig. 3. (A) Results with $0.35 \mu \mathrm{M}$ IN. Products greater than the 45-nucleotide contiguous substrate, labeled U5 joined, represent U5 ends that were inserted into the 45-nucleotide minusstrands. $(B)$ Results with $3.5 \mu \mathrm{M}$ IN. $(C)$ A plot of the appearance of U3 and U5 processed products, as well as U5 joined products, vs. time. $(D)$ Schematic representation of the synapsed-end substrate with a 2 -bp plus-strand gap.
A

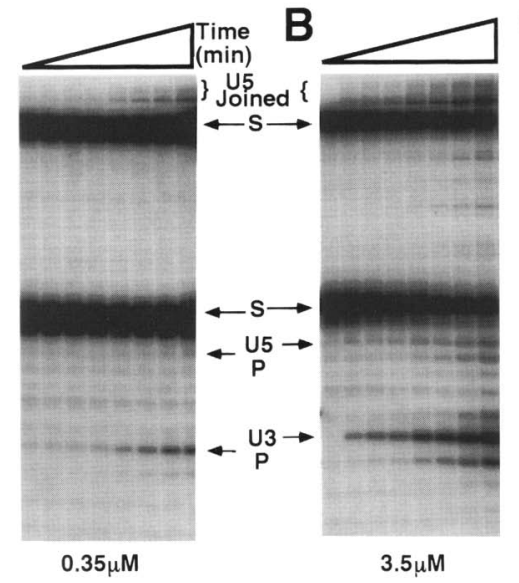

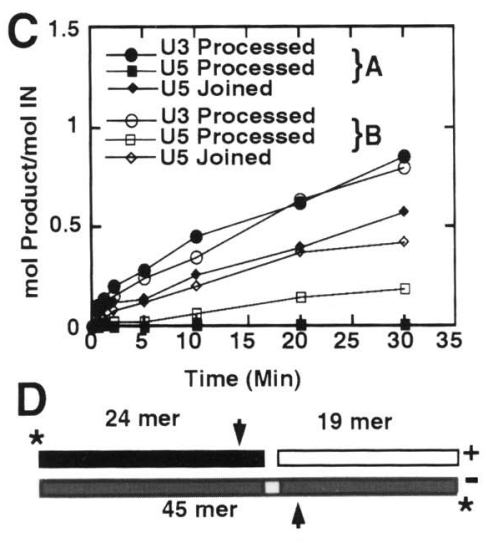

ester bond and the torsional relief is provided by a "nick" between the U5 and U3 segments. ASV IN processing of this substrate was greatly diminished as compared to U5-2-U3(+) (Fig. 6A); $<0.2$ mole of U3 product/mole IN was detected in a 50-min reaction and no U5 processing or joining was detected. The U5-4-U3|+| substrate has a 4-nucleotide single-stranded tether and thereby separates the conserved CA sequences by 8 nucleotides. No processing was detected at either site with this sub-
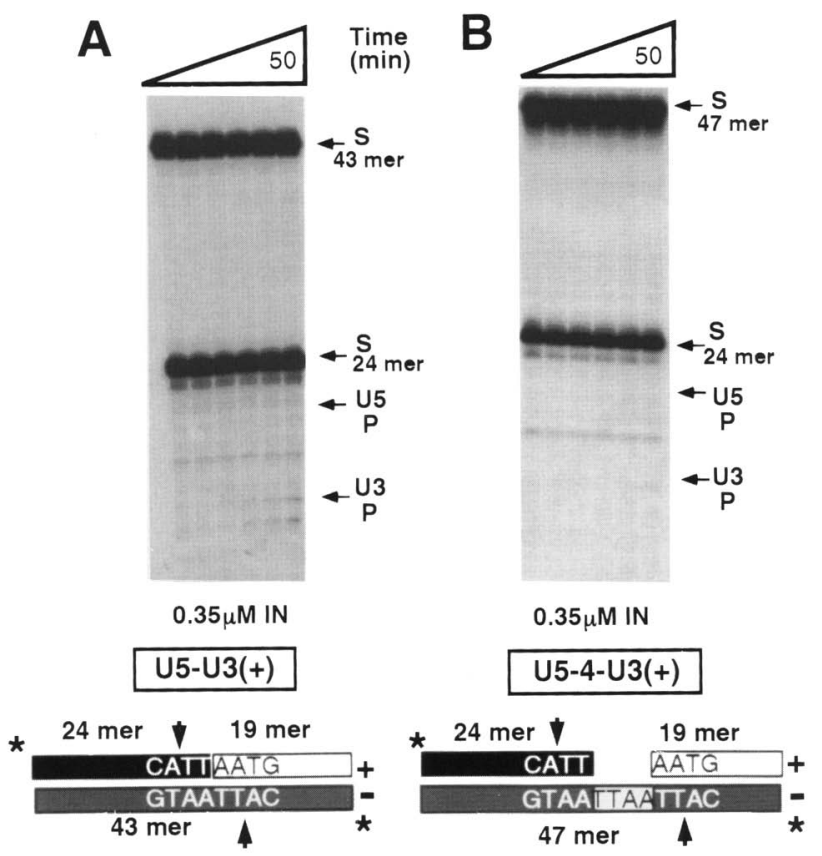

Figure 6. Effect of gap length on ASV IN processing of additional synapsed-end substrates. Substrates contain a contiguous viral minus-strand with either no additional nucleotides between the U5 and U3 junctions [U5-U3(+ |], or with an extra 4-nucleotide $\left(5^{\prime}\right.$-AATT-3') sequence between the U5 and U3 junctions [U5-4-U3(+)]. Methods of analysis and labeling conventions are as described in the legend to Fig. $3 ;(A)$ Results with $0.35 \mu \mathrm{M}$ IN and the U5-U3(+) substrate; $(B)$ results with 0.35 $\mu \mathrm{M}$ IN and the U5-4-U3(+) substrate. strate (Fig. 6B). Similarly, no processing was detected with the U5-4-U3|- ) substrate that contained a 4-nucleotide tether on the plus-strand (data not shown). These results indicate that optimal separation between processing sites is provided by the 2-nucleotide linker. This separates the conserved CA processing sites by $6 \mathrm{bp}$ and is equivalent to the length of the staggered cut made by ASV IN during insertion of these ends into target DNA.

\section{Sequence and temporal specificity in synapsed-end processing}

To investigate the sequence requirements for the processing of the synapsed-end substrate, we constructed an analog of U5-2-U3|+ | in which the conserved CA in the U5 end was changed to GC (Fig. 7A). We observed that processing and joining at the U5 site was abolished, as expected. Most importantly, however, processing at the U3 site, which contained a wild-type sequence, was also significantly reduced at low IN concentrations. (The graph in Fig. 7A compares IN processing of the U3 site on a wild-type synapsed-end substrate to a synapsed-end substrate with a singly mutated U5 site.) The dependence of enhanced processing activity on specific sequence recognition at both viral DNA ends also was demonstrated with an asymmetrically modified analog in which the CA in the U3 end was changed to GC. This substrate was not cleaved by ASV IN at the U3 site and was processed poorly at the unmodified U5 site (data not shown).

The temporal coordination of processing at paired ends in the synapsed substrate was studied with the asymmetrically modified construct ProU5-2-U31+) (Fig. 7B). This substrate had no sequence substitutions but lacked the terminal TT dinucleotide from the U5 plus-strand and represented synapsed ends in which a "preprocessed" U5 terminus was located 6 nucleotides from the unprocessed U3 "CA" sequence. Analysis of the ASV IN cleavage at the U3 site enabled us to determine whether U3 and U5 ends must be processed simultaneously to maintain the enhanced rate observed with the U5-2$\mathrm{U} 3(+)$ substrate and whether enhanced catalytic pro- 

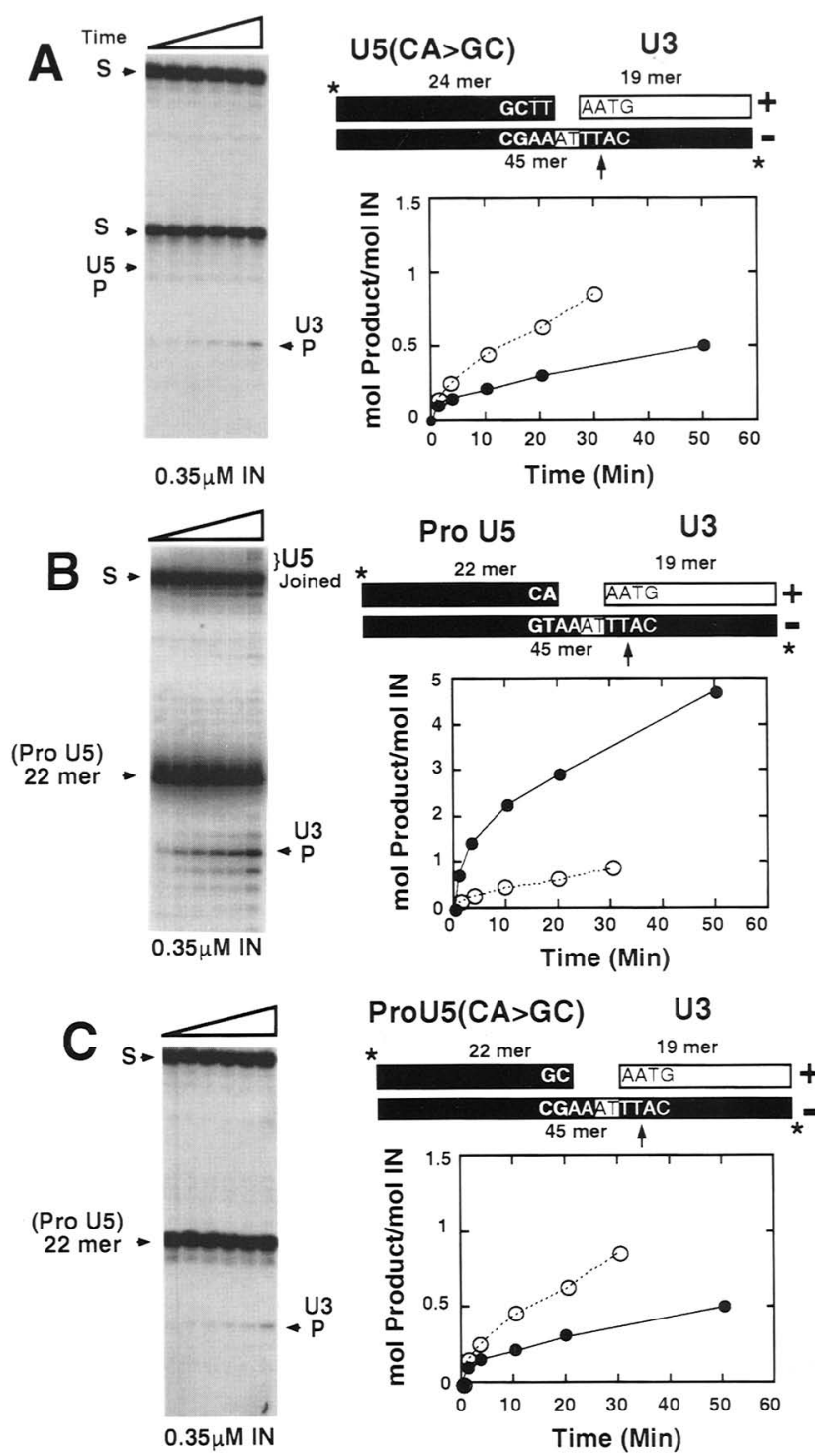

Figure 7. Processing of wild-type U3 ends that are synapsed to modified U5 ends. (A) The optimally spaced, synapsed-end substrate $\mathrm{U} 5(\mathrm{CA} \rightarrow \mathrm{GC})-2-\mathrm{U} 3(+)$ is a plus-strand gapped substrate encoding a mutated U5 and wild-type U3 end. Methods of analysis and conventions for labeling are described in the legend to Fig. 3. Data in the graphs compare U3 processing of the mutant substrate (O) with the nonmutated $(w t)$ U5-2-U3|+||O|. $(B)$ Results with ProU5-2-U3|+1, an optimally spaced, synapsedend substrate with a plus-strand gap and containing a wild-type preprocessed U5 end and a wild-type U3 end. Data in the graph are compared to wild type as described in $A .(C)$ Results with ProU5/CA $\rightarrow$ GC)-2-U3(+) a synapsed-end substrate with a plus-strand gap, containing a pre-processed and mutated (CA $\rightarrow \mathrm{GC})$ U5 sequence linked to a wild-type U3 end. Data in the graph are compared to wild type as described in $A$.

cessing at the paired ends can be uncoupled temporally. The results showed that an unprocessed U3 end, when paired with a preprocessed U5 end (Fig. 7B), was cleaved at a rate that was even higher than the enhanced rate observed with U5-2-U3 $|+|$. Thus, it is clear that pro- cessing at paired ends in the tethered substrate need not be synchronous. To investigate the sequence requirements of this reaction, we combined a mutated "preprocessed" U5-end with a wild-type U3-end in the substrate ProU5(CA $\rightarrow$ GC)-2-U3(+) (Fig. 7C). As illustrated by the graph in Figure $7 \mathrm{C}$, the processing rate at the $\mathrm{U} 3$ site with this substrate was much lower than that obtained with the analogous "wild-type" U5-2-U3|+ | substrate. Thus, the dramatically enhanced cleavage observed with ProU5-2-U3 $|+|$ is not simply a consequence of removing the terminal TT dinucleotide from the U5 plus strand. We conclude that enhanced processing can be uncoupled temporally yet still requires specific sequences at two properly positioned ends. Hence, the coordinated interactions that mediated the enhanced cleavage at U3 and U5 sites must occur at a step that precedes catalysis at the DNA ends.

\section{HIV-1 IN processing of synapsed-end substrates}

The general applicability of utilizing unprocessed synapsed-end substrates that resemble synapsed viral DNA ends was tested with the HIV-I IN and appropriately designed substrates. Figure 8 depicts a schematic of the HIV-1 DNA substrate U5-1-U3(-1, a synapsed-end substrate containing 24-bp U5 segments and 19-bp U3 segments that are linked covalently by a single deoxynucleotide (A) across the viral plus-strand. Figure 8A shows the time-dependent appearance of HIV-1 IN-processed $\mathrm{U} 5$ and $\mathrm{U} 3$ products from this substrate. As noted with single-end substrates (LaFemina et al. 1991), the HIV-1 IN preferentially processes the U5 end in the synapsedend analog; after a 90-min reaction, $\sim 90 \mathrm{nM}$ of substrate

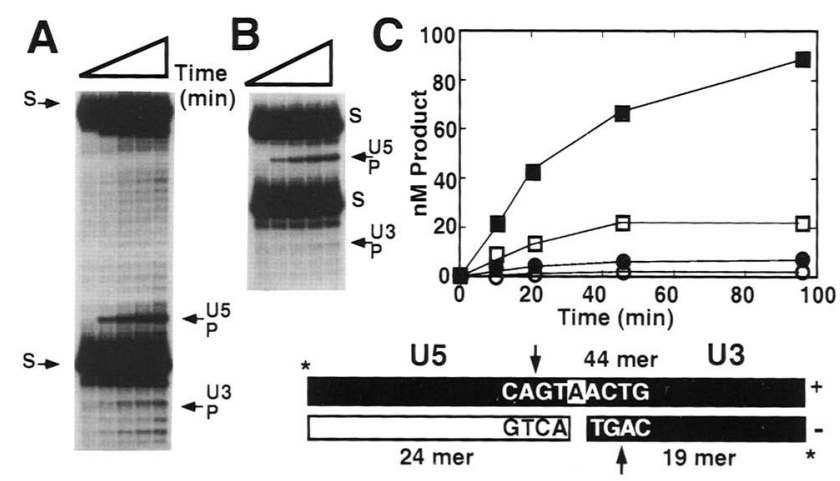

Figure 8. Enhanced HIV-1 IN processing of synapsed-end substrates. (A) Results with the substrate U5-1-U3(-) that contains a single nucleotide (A) tether on the plus strand. HIV-1 IN processing assay conditions ( $1 \mu \mathrm{M}$ substrate and $1 \mu \mathrm{M}$ HIV-1 IN) are described in Materials and methods. Methods of analysis and conventions for labeling are as described in the legend to Fig. 3. $(B)$ Results with a mixture of equivalent amounts of nontethered 24-bp HIV-1 U5 duplex and 19-bp HIV-1 U3 duplex. (C) Results are plotted as the concentration of product generated with time. Squares represent U5; circles represent U3 products. Solid symbols indicate processing of synapsed-end substrates; open symbols show processing of nontethered ends. 
was converted to U5 product, whereas $\sim 10 \mathrm{nM}$ of the substrate was processed at the U3 end. Figure $8 \mathrm{~B}$ shows results of a control experiment that included a mixture of uncoupled, single-end HIV-1 substrates at analogous concentrations ( $1 \mu \mathrm{M}$ of each end) and identical conditions. HIV-1 IN processing of single ends was much lower than observed with the synapsed-end substrate; only $20 \mathrm{nM}$ of the U5 duplex was processed after $90 \mathrm{~min}$ and no U3 processing was detected. These differences at the extended times in the processing reaction are probably an underestimate of substrate preference because initial reaction rates $(0-3 \mathrm{~min})$ with the U5-1-U3(-) substrate show $>10$-fold differences over uncoupled substrates.

The separation between the conserved CA cleavage sites in U5-1-U3(-) is 5 nucleotides and is equivalent to the separation between the staggered cuts made by HIV-I IN in coordinated joining to target DNA. To test the hypothesis that there is a correlation between the separation in paired processing and joining sites, we constructed the HIV-1 substrate U5-2-U3|-1, which has a 2-nucleotide plus-strand linker and thereby separates the two cleavage sites by 6 nucleotides, as is optimal for ASV IN. This linker also creates a unique $A p a$ LI site that has been used for other purposes. Figure 9A shows that HIV-1 IN processing of this substrate was diminished greatly as compared to U5-1-U3|-1; only $20 \mathrm{nM}$ of substrate was processed at the U5 end and $<0.5 \%$ was processed at the U3 end after a 90-min reaction. These results indicate that the optimal separation between HIV-1 IN processing sites is provided by the 1-nucleotide linker and, as with ASV IN, suggests a symmetry in the spacing between paired processing sites and joining sites.

A dependence of enhanced HIV-1 IN processing on specific sequence recognition of both viral DNA ends also was demonstrated using a modified analog of U5$1-\mathrm{U} 3|-|$ in which the conserved CA in $\mathrm{U} 3$ was changed to a GC. This mutated substrate was not cleaved at the U3 end and also showed reduced processing of the U5 end (Fig. 9B). Thus, as with ASV IN, the enhancement in HIV-1 IN processing provided by the synapsed-end substrate is dependent on a specific spacing and sequence of the two viral DNA ends.

\section{Discussion}

Biochemical processing and joining of retroviral DNA termini to host chromatin is mediated by the interaction of IN with the two ends of a linear DNA copy of the viral genome. Interactions with the DNA termini are apparently coordinated in vivo. A hallmark of the integration reaction is the production of short direct repeats flanking the proviral DNA that is analogous to the generation of target site duplications by other transposable elements (Shapiro 1979). Despite this indirect evidence for twoend interactions, the standard in vitro assays for processing and joining, which use short oligodeoxynucleotide duplexes that represent single ends (Katzman et al. 1989; Craigie et al. 1990; Katz et al. 1990), do not reveal efficient coordinated interactions. We have designed a series
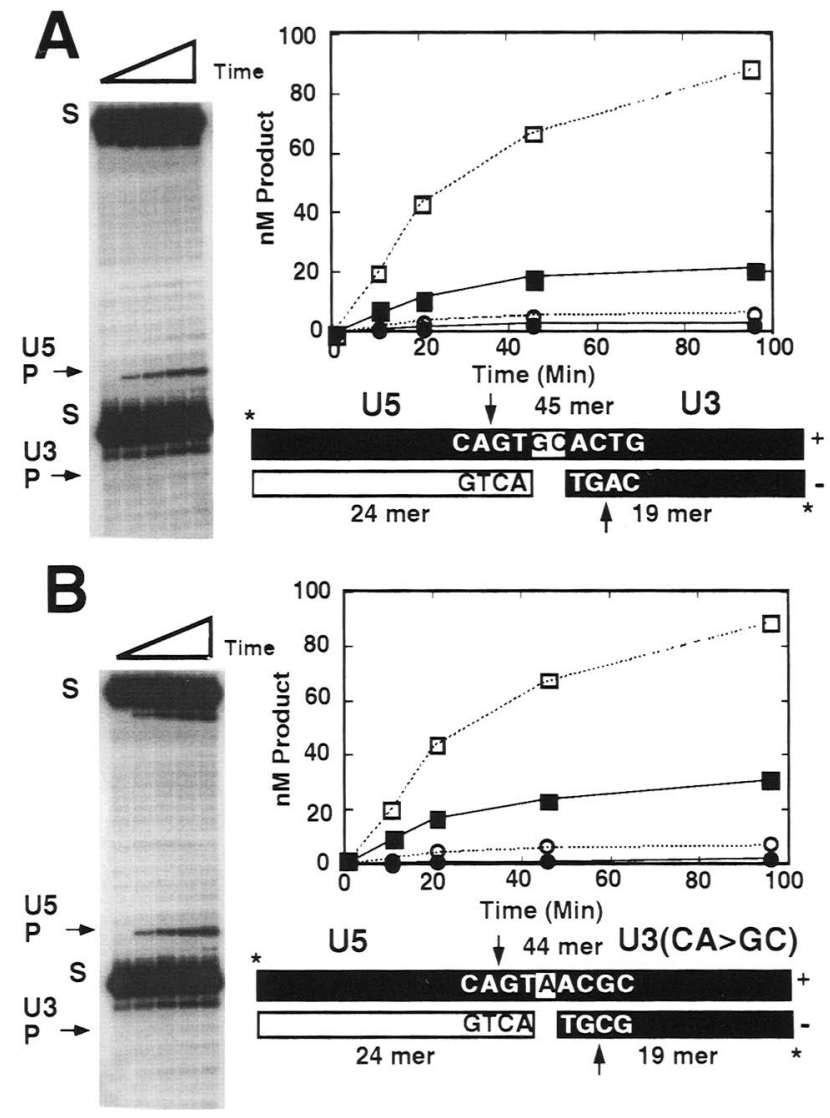

Figure 9. Processing of modified HIV-1 synapsed-end substrates. Methods of analysis and conventions for labeling are as described in the legend to Fig. 3. (A) Results with the substrate U5-2-U3(-1, which contains a contiguous viral plus-strand with an extra 2 -nucleotide $\left(5^{\prime}-\mathrm{GC}-3^{\prime}\right)$ sequence between the U5 and $\mathrm{U} 3$ junctions. The graph compares the amounts of U3 and U5 product formed from U5-2-U3 $-1 \mid 0$ and $\mathbf{\square}$, respectively) with that from the optimally spaced U5-1-U3 $(O$ and $\square)$. (B) Results with the substrate U5-1-U3|- |[CA $\rightarrow$ GC], which contains a wild-type U5 end tethered to a mutated U3 end. The graph compares amounts of U3 and U5 products formed from the mutated substrate ( $\mathbf{O}$ and $\boldsymbol{\square}$, respectively) with the nonmutated U5-1-U3(-) (O, $\square)$.

of novel substrates to facilitate the analysis of coordinated interactions at two viral DNA ends in vitro. The design is built upon accepted models for retroviral DNA integration and transpositional insertion, which predict that IN-bound preintegration intermediates synapse the viral DNA termini.

\section{IN interacts efficiently with two viral ends}

The oligodeoxynucleotide substrates for ASV IN, U5-2$\mathrm{U} 3|+|$ and $\mathrm{U} 5-2-\mathrm{U} 3 \mid-1$, juxtapose the U3 and U5 DNA ends in a configuration that clearly enhanced reactivity with the purified enzyme. The estimate of initial processing rates at each of the two ends of the synapsed substrates is approximately 10-fold higher than that of an analogous mixture of nontethered ends (Fig. 3). En- 
hanced processing of similar magnitude was also observed with HIV-1 IN and an appropriate tethered substrate (Fig. 8).

A coordinated interaction between IN and two viral DNA ends is predicted from an analysis of the activities of retroviral preintegration complexes isolated from infected cells (Brown et al. 1987; Bowerman et al. 1989; Ellison et al. 1990; Farnet and Haseltine 1990; Lee and Coffin 1990). Pairwise joining of blunt and preprocessed viral DNA termini also has been reconstituted under specialized in vitro conditions (Fitzgerald et al. 1992; Vora et al. 1994; A.P. Aiyar, A.M. Skalka, and J. Leis, in prep.). The juxtaposition of two viral DNA ends has been visualized by electron microscopy of reconstituted complexes in which viral DNA sequences are bridged with purified ASV IN (Grandgenett et al. 1993). Such complexes are reminiscent of those formed between many prokaryotic transposases and the ends of the corresponding transposable elements/Craigie and Mizuuchi 1987; Surrette et al. 1987; Bainton et al. 1991; Haniford et al. 1991). The retroviral IN complexes must couple the U3 and U5 termini because they insert two viral DNA ends in a distinctive staggered fashion. However, the synapsed-end substrates constructed for these studies provide the first biochemical evidence that IN interacts more efficiently with synapsed DNA ends.

The necessity for higher order IN-DNA association is predicted from biochemical and genetic studies that indicate that both the ASV and HIV-1 INs function as multimers (Jones et al. 1992; Engleman et al. 1993; van Gent et al. 1993). The $K_{\mathrm{d}}$ for ASV and HIV-1 IN homodimerization are in the micromolar range (Jones et al. 1992; Hickman et al. 1994). Our results with ASV IN demonstrate that this enzyme can act on synapsed-end substrates at a concentration below its estimated $K_{\mathrm{d}}$ for selfassociation. This suggests that the synapsed-end substrates may facilitate IN self-association, IN-DNA association, or cooperatively influence both types of interactions. We note that tandem recognition sites are a hallmark of many multimeric DNA-binding proteins that bind cooperatively.

\section{Observations of relevance to structural aspects of integrative recombination}

Our analyses indicate that the optimal separation between paired processing sites in the synapsed-end substrates is 6 nucleotides for ASV IN and 5 nucleotides for HIV-1 IN. Results with both enzymes show that processing was reduced greatly with substrates in which the tether was slightly longer or shorter (Figs. 6 and 9) than the predicted optimum. The optimal spacing between paired processing sites for the ASV and HIV-1 IN is the same as the lengths, in nucleotides, of direct repeats of target DNA that are produced as a consequence of viral DNA integration (Hishinuma et al. 1981; Muesing et al. 1985). This length is also equivalent to the optimal target DNA gap between two HIV-1 viral DNA ends in "crossbones" substrates for two-ended "disintegration" reactions catalyzed by HIV-1 IN /Chow and Brown 1994). As noted below, the optimal spacing between viral DNA termini provides an estimate of the distance between catalytic sites in the IN-DNA complex.

The synapsed-end substrates permitted efficient IN processing of viral-specific sites that were embedded within a discontinuous double-stranded DNA molecule. Each of the "termini" in these structures has only one of the two DNA strands to be cleaved in the normal subterminal position. The fact that both $3^{\prime}$ and $5^{\prime}$ ends need not be in their normal position for processing to occur is consistent with results from Vink et al. (1991) who noted that extensions of either strand at the terminus of a single-end HIV-1 oligonucleotide substrate are tolerated without significantly affecting IN processing.

Our experiments also showed that substrates with a contiguous double-strand linking U3 and U5 ends were processed inefficiently by ASV IN. This is consistent with previously noted failures of double-stranded long terminal repeat (LTR-LTR) junctions, cloned within retroviral genomes, to be utilized by IN as authentic sites in vivo (Ellis and Bernstein 1989; Lobel et al. 1989) or in vitro (Duyk et al. 1985). We interpret our in vitro results as implying a need for torsional and/or rotational flexibility at the processing sites. The flexibility allowed by a single-stranded tether permits angular rotation between two sites. If, as our data suggest, the two ends are not aligned linearly during IN cleavage, the distance between synapsed processing sites could extend well beyond the $20 \AA$ predicted for an analogous B-DNA duplex (Fig. 10). An extended distance is consistent with the prediction, based on X-ray crystallographic analyses, that the catalytic sites in homodimers of the HIV-1 IN and ASV IN catalytic domains are separated by $35-40 \AA$ (Dyda et al. 1994; Bujacz et al. 1995).

Specific spatial alignment of the juxtaposed DNA termini (Fig. 2A) may facilitate cooperative interaction between IN subunits that bind the U3 and U5 ends. The greatly enhanced processing observed with the synapsedend substrates suggests that IN has a higher affinity for them than for single ends. Many dimeric DNA-binding proteins that bind operators with two sites show cooperative binding and are also sensitive to the configuration between the DNA recognition sites. For example, the affinity of the phage 434 repressor for an operator can be increased by introducing a single-strand nick in the region linking two operator half-sites (Koudelka et al. 1988). Measurements of the energetics of DNA twisting suggest that the single-stranded gaps between the binding sites can affect torsional relief to better accommodate protein binding (Koudelka and Carlson 1992). Retroviral INs may also require a significant degree of torsional relief through helical unwinding at the processing sites. This would be consistent with a noted increase of IN activity on single-ended HIV-1 and ASV substrates that have artificially unwound DNA termini through heteroduplexes introduced in the terminal 2 bp (van den Ent et al. 1994; B. Müller and A.M. Skalka, unpubl.). Severe distortion of the DNA helix, such as occurs in chromatin packing, also provides a favorable target site 


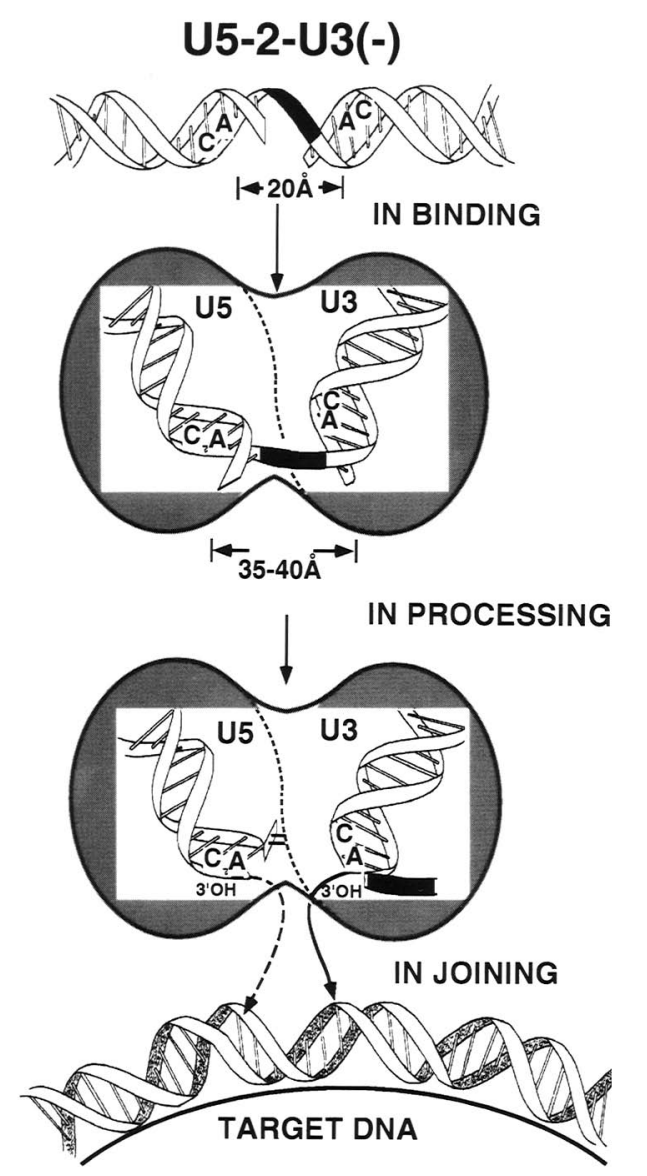

Figure 10. A model for the alignment of synapsed-end substrates by retroviral integrases. The linear B-DNA form of juxtaposed U5 and U3 retroviral DNA ends that are tethered by a single strand of DNA (shaded helical segment) separates the two processing sites by $\sim 20 \AA$. The flexibility of the tether permits repositioning of the processing sites to accommodate the separation of catalytic sites in an IN multimer. Processing exposes the $3^{\prime} \mathrm{OH}$ at each of the ends that are joined to target DNA. Although the target DNA strands, even those wound around a nucleosome might have less than the predicted $(35-40 \AA$ spacing, the first nucleophilic attack on the target DNA by one of the $3^{\prime}$ ends could introduce torsional relief at the target site. This would then facilitate the sequential insertion of the second viral 3 ' end, using the same or symmetrically paired catalytic sites in the IN multimers.

for joining (Pryciak and Varmus 1992; Pruss et al. 1994). A similar distortion may be required of the donor DNA ends during processing.

\section{Implications for IN function}

The synapsed-end substrates offer a unique means of examining particular aspects of the coordinated interactions of IN with two viral ends. We were able to alter the sequence at either end and examine the effects on enzyme activity at both ends. The results showed that mutation of the conserved CA dinucleotide of a single end in a tethered pair caused not only an inhibition of processing at the altered end but also dimin- ished processing at the wild-type end (Fig. 8). This could reflect a decreased affinity of IN protomers for such a substrate. Multimeric proteins that associate cooperatively with tandem sequence-specific DNA-binding sites are known to display a decreased affinity for adjacent sites when a single site is mutated (Ptashne 1986). This result also suggests that the multimeric IN complex, which ultimately must insert both ends of retroviral DNA into a target site, is "cognizant" of the sequence at both viral DNA ends. Murphy and Goff (1992) have performed a similar experiment with mutant MuLV in vivo. They showed that constructs encoding single-end alterations of U3 sequence were unable to integrate and that processing of both U3 and U5 ends was inhibited. Their results predict that sequence-specific interactions with both ends are required for efficient processing. Similar observations with singly mutated ends in a number of transposable elements suggests that binding and bridging of both element ends is a prerequisite to cleavage (Burlingame et al. 1986; Surrette et al. 1991; Mizuuchi et al. 1992; Haniford and Kleckner 1994; Sharon et al. 1994). Our results provide direct biochemical support for these predictions.

The synapsed-end substrates also have allowed us to analyze the effect of including a preprocessed end in a synapsed complex. We observed that ASV-IN cleavage of the unprocessed end was not diminished in such substrates. On the contrary, the rate was significantly enhanced. Thus, we conclude that there is no requirement for tight temporal coupling between cleavages at synapsed ends. This is consistent with analysis of the ends of unintegrated viral DNA isolated from newly infected cells (Kulkosky et al. 1990; Vora et al. 1990; Lee and Coffin 1991), where unintegrated HIV-1 and ASV DNAs that lack the terminal 2 nucleotides from either the U5 or the U3 end represent apparently uncoupled IN-processing of retroviral DNA ends in vivo. This may be a general phenomenon among transposable elements because cleavages at the ends of both $\operatorname{Tn} 7$ and $\operatorname{Tn} 10$ can also be asynchronous (Bainton et al. 1991; Haniford and Kleckner 1994). A sequential cleavage mechanism has also been proposed to account for the asymmetric organization of the $\gamma \delta$ resolvase dimer complexed with a cleavage site (Yang and Steitz 1995). It seems possible that cleavage of the target DNA during the joining reaction may also be sequential (Fig. 10).

The significant enhancement of IN reactivity with an unprocessed end that is tethered to a preprocessed end suggests that IN may have a higher affinity for substrates with preprocessed ends. Alternatively, because these substrates also possess longer single-stranded tethers, they may provide additional flexibility in the intervening region that could also contribute to the enhanced reactivity. In either case, results with this modified tethered substrate imply that the coordinated IN interactions that result in an enhanced reactivity are independent of (or precede) the cleavage step. This lends further support to our suggestion that the enhanced reactivity with the tethered-end is manifested at the level of DNA 
binding through cooperative associations with juxtaposed sites.

The synapsed-end substrates described in this report have allowed us to address important aspects of the interaction of IN and retroviral DNA ends prior to integration. They should prove useful in further studies of the mechanism of integration. Additionally, enhanced IN reactivity with these analogs may facilitate screening for inhibitors to be used as leads in the development of effective antiviral therapies.

\section{Materials and methods}

\section{Purification of INs}

ASV IN was purified from Escherichia coli strain MC1061, which contains plasmids pRK248cIts and pRC23p32-IN that encode a $\lambda$ thermosensitive repressor and the ASV-IN, respectively (Terry et al. 1988). Cells were grown, harvested, and lysed, and the ASV IN was purified as described previously (Jones et al. 1992) with some minor modifications (G. Merkel and A.M. Skalka, unpubl.). Aliquots of purified protein were stored at $-70^{\circ} \mathrm{C}$ in storage buffer [50 mM HEPES (pH 8.1), $0.5 \mathrm{M}$ $\mathrm{NaCl}, 1 \%$ (vol/vol) thiodiglycol, $0.1 \mathrm{~mm}$ EDTA, 40\% (vol/vol) glycerol] for extended periods, whereas working stocks were routinely stored at $-20^{\circ} \mathrm{C}$. ASV IN concentration was quantitated by the method of Bradford (Bio-Rad) and adjusted by a correction factor of 0.8 , as determined from direct amino acid analysis.

HIV-1 IN was purified from E. coli strain $\mathrm{DH} 5 \alpha \mathrm{F}^{\prime}$, which contains the plasmid pKK223-NY5IN-NdeI, as described previously (Holler et al. 1993). The purified protein was stored in buffer [20 mM HEPES (pH 7.5), $0.5 \mathrm{M} \mathrm{KCl}, 0.1 \mathrm{~mm}$ EDTA, $1 \mathrm{~mm}$ DTT, $40 \%$ glycerol] at $-20^{\circ} \mathrm{C}$.

\section{Oligodeoxynucleotide substrate}

Substrates were prepared based on U5 and U3 HIV-1 or ASV sequences. Oligodeoxynucleotides were synthesized on an ABI DNA synthesizer by the Fox Chase Cancer Center Core DNA Synthesis Facility. DNA was purified by electrophoresis through $17 \%$ polyacrylamide gels containing $7 \mathrm{M}$ urea, electroeluted from gel slices in an Amicon Centrilutor, desalted, and concentrated in an Amicon Centricon ( 3000 m.w. cutoff).

Single-stranded oligodeoxynucleotides were radioactively labeled at the $5^{\prime}$ end with $\left[\gamma^{-32} \mathrm{P}\right] \mathrm{ATP}(7000 \mathrm{Ci} / \mathrm{mmole}$; ICN Biomedical) and $\mathrm{T} 4$ polynucleotide kinase (New England Biolabs). Labeling was terminated by the addition of EDTA to $10 \mathrm{~mm}$, and the kinase was heat inactivated at $65^{\circ} \mathrm{C}$ for $20 \mathrm{~min}$. The appropriate strands were mixed at equimolar concentrations in 20 $\mathrm{mM}$ Tris ( $\mathrm{pH} 8), 50 \mathrm{~mm} \mathrm{NaCl}$, and heated for $10 \mathrm{~min}$ at $90^{\circ} \mathrm{C}$, followed by slow cooling to room temperature over $\sim 5 \mathrm{hr}$. The substrates were ethanol-precipitated three times to remove unincorporated ATP and suspended in $20 \mathrm{~mm}$ Tris $(\mathrm{pH} 8)$ and 50 $\mathrm{mM} \mathrm{NaCl}$. The integrity of the substrates was monitored by analysis of samples on native $10 \%$ polyacrylamide gels at $4^{\circ} \mathrm{C}$ and by verifying that labeled oligonucleotides annealed to form a predominant duplex of expected size.

\section{IN processing assays and quantitation}

ASV IN processing assays were performed at $37^{\circ} \mathrm{C}$ in $20 \mathrm{~mm}$ Tris- $\mathrm{HCl}(\mathrm{pH}$ 8), $5 \mathrm{~mm}$ HEPES (pH 8.1), $10 \mathrm{~mm}$ 2-mercaptoethanol, $50 \mu \mathrm{g} / \mathrm{ml}$ of bovine serum albumin, $5 \mathrm{mM} \mathrm{MnCl}_{2}, 4 \%$ (vol/vol) glycerol, $100 \mathrm{mM} \mathrm{NaCl}, 10 \mu \mathrm{M}$ of the indicated $5^{\prime}$ - labeled oligonucleotide duplex, and indicated amounts of ASV IN. IN was freshly diluted to appropriate concentrations in storage buffer, and $1 \mu \mathrm{l}$ of this dilution was added to a final $10-\mu 1$ reaction. Each reaction contained $1 \times 10^{6} \mathrm{cpm}$ of radiolabeled substrate, plus unlabeled substrate, at a final concentration of $10 \mu \mathrm{M}$. After indicated lengths of incubation, $1-\mu \mathrm{l}$ samples were removed and quenched in $13 \mu \mathrm{l}$ of formamide loading buffer and then a $7-\mu \mathrm{l}$ aliquot was analyzed by denaturing PAGE $(17 \%$ polyacrylamide, $7 \mathrm{M}$ urea).

HIV-l IN processing assays were performed at $37^{\circ} \mathrm{C}$ as described previously (Kulkosky et al. 1995). Briefly, $1 \mu \mathrm{M}$ HIV-1 IN and $1 \times 10^{6} \mathrm{cpm}$ of radiolabeled substrate, plus unlabeled substrate, at a final concentration of $1 \mu \mathrm{M}$ were incubated in a $15-\mu \mathrm{l}$ reaction volume containing $10 \mathrm{mM}$ Tris $(\mathrm{pH} 7.4), 2 \mathrm{mM}$ HEPES (pH 7.5), $10 \mathrm{mM} \mathrm{MnCl}$, 6.6\% DMSO, 9\% glycerol, $0.1 \mathrm{mM}$ DTT, and $50 \mathrm{~mm} \mathrm{KCl}$. At the indicated time points $2.5-\mu \mathrm{l}$ aliquots were removed, quenched, and subjected to electrophoresis as described above.

Gels were exposed to imaging plates (Fuji, Japan), and the amount of product for each reaction was calculated from the fraction of total radioactivity present in the appropriate bands using the MacBas 1000 Bio-Imaging Analyzer (Fuji, Japan). Results were normalized to the amount of ASV-IN used in the reactions to facilitate a comparison between the different substrates and different enzyme concentrations. Under the conditions described in these studies, processing was the major activity of IN observed. Loss of substrate could be accounted for almost entirely by the sum of -2 and -3 cleavage products; the only exception was with the U5-2-U3|+| substrate. In this case, joined products also were included in the quantitative analysis.

\section{Acknowledgments}

We thank Chantal Autexier, Jan Feng, Richard Katz, David Lazinski, and Jonathan Leis for critical reading of the manuscript. We are grateful to Ernest Assante-Appiah and Joseph Kulkosky for providing preparations of purified HIV-1 IN, and to George Merkel for his continued help in purifying ASV IN. Richard Katz, Barbara Müller, and Mark Andrake have provided encouragement and helpful advice throughout this project. This work was supported by National Institutes of Health grants CA47486, CA06927, a grant for infectious disease research from Bristol-Myers Squibb Foundation and also by an appropriation from the Commonwealth of Pennsylvania. G.K. was supported, in part, by a postdoctoral fellowship from the Medical Research Council of Canada.

The publication costs of this article were defrayed in part by payment of page charges. This article must therefore be hereby marked "advertisement" in accordance with 18 USC section 1734 solely to indicate this fact.

\section{References}

Bainton, R., P. Gamas, and N.L. Craig. 1991. Tn7 transposition in vitro proceeds through an excised transposon intermediate generated by staggered breaks in DNA. Cell 65: 805-816.

Bowerman, B., P.O. Brown, J.M. Bishop, and H.E. Varmus. 1989. A nucleoprotein complex mediates the integration of retroviral DNA. Genes \& Dev. 3: 469-478.

Brown, P.O., B. Bowerman, H.E. Varmus, and J.M. Bishop. 1987. Correct integration of retroviral DNA in vitro. Cell 4: 347356.

Bujacz, G., M. Jaskolski, J. Alexandratos, A. Wlodawer, G. Merkel, R.A. Katz, and A.M. Skalka. 1995. High resolution structure of the catalytic domain of avian sarcoma virus integrase. I. Mol. Biol. (in press). 
Burlingame, R.P., M.G. Obukwicz, D.L. Lynn, and M.M. Howe. 1986. Isolation of point mutations in bacteriophage $\mathrm{Mu}$ attachment regions cloned in a $\lambda:$ :mini-Mu phage. Proc. Natl. Acad. Sci. 83: 6012-6016.

Chow, S.A and P.O. Brown. 1994. Juxtaposition of two viralDNA ends in a bimolecular disintegration reaction mediated by multimers of human-immunodeficiency-virus type-1 or murine leukemia-virus integrase. I. Virol. 68: 7869-7878.

Chow, S.A., K.A. Vincent, V. Ellison, and P.O. Brown. 1992. Reversal of integration and DNA splicing mediated by integrase of human immunodeficiency virus. Science 25: 723-726.

Craigie, R. and K. Mizuuchi. 1987. Transposition of Mu DNA: Joining of $\mathrm{Mu}$ to target DNA can be uncoupled from cleavage at the ends of Mu. Cell 51: 493-501.

Craigie, R., T. Fujiwara, and F. Bushman. 1990. The IN protein of Moloney murine leukemia virus processes the viral DNA ends and accomplishes their integration in vitro. Cell 62: 829-837.

Duyk, G., M. Longiaru, D. Cobrinik, R. Kowal, P. deHaseth, A.M. Skalka, and J. Leis. 1985. Circles with two tandem long terminal repeats are specifically cleaved by pol gene-associated endonuclease from avian sarcoma and leukosis viruses: Nucleotide sequences required for site-specific cleavage. $I$. Virol. 56: 589-599.

Dyda, F., A.B. Hickman, T.M. Jenkins, A. Engleman, R. Craigie, and D.R. Davies. 1994. Crystal structure of the catalytic domain of HIV-1 integrase: Similarity to other polynucleotide transferases. Science 266: 1981-1986.

Ellis, J. and A. Bernstein. 1989. Retrovirus vectors containing an internal attachment site: Evidence that circles are not intermediates to murine retrovirus integration. I. Virol. 63: 28442846.

Ellison, V., H. Abrams, T. Roe, J. Lifson, and P.O. Brown. 1990. Human immunodeficiency virus integration in a cell-free system. /. Virol. 64: 2711-2715.

Engleman, A., F.D. Bushman, and R. Craigie. 1993. Identification of discrete functional domains of HIV-1 integrase and their organization within an active multimeric complex. EMBO I. 12: 3269-3275.

Farnet, C.M. and W.A. Haseltine. 1990. Integration of human immunodeficiency virus type 1 DNA in vitro. Proc. Natl. Acad. Sci. 87: 4164-4168.

Fitzgerald, M.L., A.C. Vora, W.G. Zeh, and D.P. Grandgenett. 1992. Concerted integration of viral-DNA termini by purified avian-myeloblastosis virus integrase. I. Virol. 66: 62576263.

Goff, S.P. 1992. Genetics of retroviral integration. Annu. Rev. Genet. 26: 527-544.

Grandgenett, D.P., R.B. Inman, A.C. Vora, and M.L. Fitzgerald. 1993. Comparison of DNA-binding and integration half-site selection by avian-myeloblastosis virus integrase. /. Virol. 67: 2628-2636.

Haniford, D.B. and N. Kleckner. 1994. Tn10 transposition in vivo: Temporal separation of cleavages at the two transposon ends and roles of terminal basepairs in subsequent interaction of ends. EMBO J. 13: 3401-3411.

Haniford, D.B., H. Benjamin, and N. Kleckner. 1991. Kinetic and structural analysis of a cleaved donor intermediate and a strand transfer intermediate in Tn10 transposition. Cell 64: 171-179.

Hickman, A.B., I. Palmer, A. Engleman, R. Craigie, and P. Wingfield. 1994. Biophysical and enzymatic properties of the catalytic domain of HIV-l integrase. J. Biol. Chem. 46: 2927929287.

Hishinuma, F., P.J. DeBona, S. Astrin, and A.M. Skalka. 1981. Nucleotide sequence of the acceptor site and termini of in- tegrated avian endogenous provirus ev-1: Integration creates a 6 bp repeat of host DNA. Cell 23: 155-164.

Holler, T.P., S.K. Foltin, Q.Z. Ye, and D.J. Hupe. 1993. HIV-1 integrase expressed in Escherichia coli from a synthetic gene. Gene 136: 323-328.

Jones, K.S., J. Coleman, G.W. Merkel, T.M. Laue, and A.M. Skalka. 1992. Retroviral integrase functions as a multimer and can turn over catalytically. I. Biol. Chem. 267: 1603716040.

Katz, R.A. and A.M. Skalka. 1994. The retroviral enzymes. Annu. Rev. Biochem. 63: 133-173.

Katz, R.A., G. Merkel, J. Kulkosky, J. Leis, and A.M. Skalka. 1990. The avian retroviral IN protein is both necessary and sufficient for integrative recombination in vitro. Cell 63: 87-95.

Katzman, M., R.A. Katz, A.M. Skalka, and J. Leis. 1989. The avian retroviral integration protein cleaves the terminal sequences of linear viral DNA at the in vivo sites of integration. J. Virol. 63: 5319-5327.

Koudelka, G.B. and P. Carlson. 1992. DNA twisting and the effects of non-contacted bases on affinity of 434 operator for 434 repressor. Nature 355: 89-91.

Koudelka, G.B., P. Harbury, S.C. Harrison, and M. Ptashne. 1988. DNA twisting and the affinity of bacteriophage 434 operator for bacteriophage 434 repressor. Proc. Natl. Acad. Sci. 85: 4633-4637.

Kulkosky, J., R.A. Katz, and A.M. Skalka. 1990. Terminal nucleotides of the preintegrative linear form of HIV-1 DNA deduced from the sequence of circular DNA junctions. $/$. Acq. Immune Def. Synd. 3: 852-858.

Kulkosky, J., R.A. Katz, G. Merkel, and A.M. Skalka. 1995. Activities and substrate specificity of the evolutionary conserved central domain of retroviral integrases. Virology 206: 448-456.

LaFemina, R.L., P. Callahan, and M.G. Cordingley. 1991. Substrate specificity of recombinant human immunodeficiency virus integrase. J. Virol. 65: 5624-5630.

Lee, Y.M.H. and J.M. Coffin. 1990. Efficient autointegration of avian retrovirus DNA in vitro. J. Virol. 64: 5958-5965.

. 1991. Relationship of avian retrovirus DNA synthesis to integration in vitro. Mol. Cell. Biol. 11: 1419-1430.

Lobel, L.I., J.E. Murphy, and S.P. Goff. 1989. The palindromic LTR-LTR junction of Moloney murine leukemia virus is not an efficient substrate for proviral integration. I. Virol. 63: 2629-2637.

Mizuuchi, M., T. Baker, and K. Mizuuchi. 1992. Assembly of the active form of the transposase-Mu DNA complex: A critical point in Mu transposition. Cell 70: 303-311.

Muesing, M.A., D.H. Smith, C.D. Cabradilla, C.V. Benton, L.A. Lasky, and D.J. Capon. 1985. Nucleic acid structure and expression of human AIDS/lymphadenopathy retrovirus. $\mathrm{Na}$ ture 313: $450-458$.

Murphy, J.E. and S.P. Goff. 1992. A mutation at one end of Moloney murine leukemia virus DNA blocks cleavage of both ends by the viral integrase in vivo. J. Virol. 66: 50925095.

Pruss, D., F.D. Bushman, and A.P Wolffe. 1994. Human immunodeficiency virus integrase directs integration to sites of severe DNA distortion within the nucleosome core. Proc. Natl. Acad. Sci. 91: 5913-5917.

Pryciak, P.M. and H.E. Varmus. 1992. Nucleosomes, DNAbinding proteins, and DNA sequence modulate retroviral integration target site selection. Cell 69: 769-780.

Ptashne, M. 1986. A genetic switch. Blackwell Scientific Publications, Palo Alto, CA.

Shapiro, J.A. 1979. Molecular model for the transposition and 
replication of bacteriophage $\mathrm{Mu}$ and other transposable elements. Proc. Natl. Acad. Sci. 76: 1933-1937.

Sharon, G., T.J. Burkett, and D.J. Garfinkel. 1994. Efficient homologous recombination of Tyl element cDNA when integration is blocked. Mol. Cell. Biol. 14: 6540-6551.

Sherman, P.A., M.L. Dickson, and J.A. Fyfe. 1992. Human immunodeficiency virus type 1 integration protein: DNA sequence requirements for cleaving and joining reactions. $J$. Virol. 66: 3593-3601.

Surrette, M.G., S.J. Buch, and G. Chaconas. 1987. Transpososomes: Stable protein-DNA complexes involved in the in vitro transposition of bacteriophage $\mathrm{Mu}$ DNA. Cell 49: 253262.

Surrette, M.G., T. Harkness, and G. Chaconas. 1991. Stimulation of the $\mathrm{Mu} \mathrm{A}$ protein-mediated strand cleavage reaction by the $\mathrm{Mu} \mathrm{B}$ protein, and requirement of DNA nicking for stable type 1 transposome formation. 1. Biol. Chem. 266: 3118-3124.

Terry, R., D.A. Soltis, M. Katzman, D. Cobrink, J. Leis, and A.M. Skalka. 1988. Properties of avian sarcoma-leukosis virus pp32-related pol-endonucleases produced in Escherichia coli. I. Virol. 62: 2358-2365.

van den Ent, F.M.I, C. Vink, and R.H.A. Plasterk. 1994. DNA substrate requirements for different activities of the human immunodeficiency virus type 1 integrase protein. $J$. Virol. 68: 7825-7832.

van Gent, D.C, C. Vink, A.A.M. Oude Groeneger, and R.H.A. Plasterk. 1993. Complementation between HIV integrase proteins mutated in different domains. EMBO J. 12: 32613268.

Varmus, H. and P.O. Brown. 1989. Retroviruses. In Mobile DNA (ed. D.E. Berg and M.M. Howe), pp. 53-108. American Society for Microbiology, Washington, D.C.

Vink, C. and R.H.A. Plasterk. 1994. The human immunodeficiency virus integrase protein. Trends Genet. 9: 433-437.

Vink, C., D.C. van Gent, Y. Elgersma, and R.H.A. Plasterk. 1991. Human immunodeficiency virus integrase protein requires a subterminal position of its viral DNA recognition sequence for efficient cleavage. J. Virol. 65: 4636-4644.

Vora, A.C., M.L. Fitzgerald, and D.P. Grandgenett. 1990. Removal of $3^{\prime}-\mathrm{OH}$-terminal nucleotides from blunt ended long terminal repeat termini by the avian retrovirus integration protein. J. Virol. 64: 5656-5659.

Vora, A.C., M. McCord, M.L. Fitzgerald, R.B. Inman, and D.P. Grandgenett. 1994. Efficient concerted integration of retrovirus-like DNA in vitro by avian myeloblastosis virus integrase. Nucleic Acids Res. 22: 4454-4461.

Yang, W. and T.A. Steitz. 1995. Crystal structure of the sitespecific recombinase $\gamma \delta$ resolvase complexed with a 34 bp cleavage site. Cell 82: 193-207. 


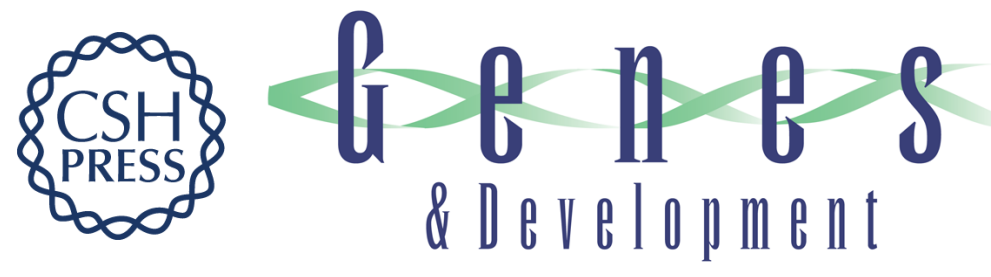

\section{Enhanced and coordinated processing of synapsed viral DNA ends by retroviral integrases in vitro.}

G Kukolj and A M Skalka

Genes Dev. 1995, 9:

Access the most recent version at doi:10.1101/gad.9.20.2556

References This article cites 52 articles, 27 of which can be accessed free at:

http://genesdev.cshlp.org/content/9/20/2556.full.html\#ref-list-1

License

Email Alerting

Service

Receive free email alerts when new articles cite this article - sign up in the box at the top right corner of the article or click here.

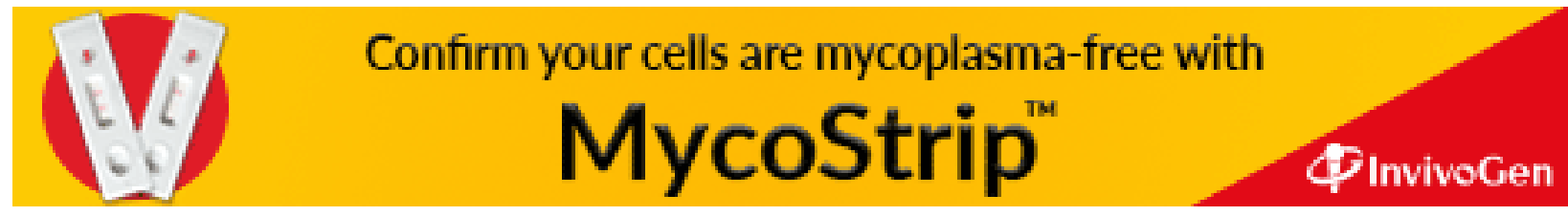

